Research Article

\title{
Experimental Investigation of an RC Slab Culvert Rehabilitated with Grouted CSPs
}

\author{
Bai-Jian Li $\mathbb{D}$, Wen-Qiang Fu, Yu-Ting He, and Xin-Sha Fu \\ School of Civil Engineering and Transportation, South China University of Technology, Guangzhou, Guangdong 510640, China \\ Correspondence should be addressed to Xin-Sha Fu; fuxinsha@163.com
}

Received 3 December 2020; Revised 10 June 2021; Accepted 15 September 2021; Published 13 October 2021

Academic Editor: Daniele Baraldi

Copyright ( $) 2021$ Bai-jian Li et al. This is an open access article distributed under the Creative Commons Attribution License, which permits unrestricted use, distribution, and reproduction in any medium, provided the original work is properly cited.

\begin{abstract}
The rehabilitation of an existing culvert with corrugated steel plates (CSPs) has been an emerging technology in recent years, but engineers and researchers are not particularly clear about the working principle of the rehabilitated structure. To investigate the mechanical properties of reinforced concrete (RC) slabs rehabilitated with CSPs, laboratory tests were carried out to explore the calculation method and influencing factors of load-carrying capacity of RC slab culverts rehabilitated with grouted CSPs. The results revealed the following: the flexural failure of the prerehabilitated RC slab has little influence on the test-loading capacity of the rehabilitated system; shear failure will occur in the RC slab and grout, and an arch effect will be formed in the CSP and grout after rehabilitation; the higher the shear strength of the concrete of the RC slab and grout, the greater the test-loading capacity of the rehabilitated system: the RC slab and grout greatly contribute to the test-loading capacity of the rehabilitated system; CSP changes the ductility of the rehabilitated system at the failure stage. It was found that the estimation method for the test-loading capacity of the rehabilitated system based on the shear capacities of the RC slab and grout and the flexural capacity of the CSP is reasonable; the maximum difference between the theoretical and experimental results was less than $30 \%$, and the minimum difference between them was $0 \%$.
\end{abstract}

\section{Introduction}

Most small bridges and culverts built early in China are mostly coming into overhaul period. Among many repair methods, the rehabilitation of small bridges and culverts with grouted corrugated steel plates (CSPs) is a very convenient technology that only requires the insertion of CSPs into the bridge or culvert and then grouting the space between them $[1,2]$. However, this technology introduces new challenges to structural analysis as the mechanical mechanism of the structure changes from a single system to a composite system of the existing bridge or culvert, grout, and corrugated steel arch after rehabilitation; the existing bridge or culvert, grout, and CSPs may play very different roles in the rehabilitated system.

A large amount of research has been conducted to investigate the performance of slip-lined pipes, and postrehabilitated pipes fixed with different materials have been found to exhibit different mechanical properties. For example, a cast-iron pipe rehabilitated with a liner has been found to act as a "pipe within a pipe" system [3], whereas a rehabilitated concrete sewer has been found to act as a composite system [4]. Moreover, the compressive strength of the grout has been found to have an important influence on the test-loading capacity of the rehabilitated pipe [5]. Both full and partial interactions have been found to occur between the existing pipe, grout, and liner, and the design of the liner should not rely on the assumption of a bond between the two components $[6,7]$. Furthermore, the level of corrosion of CSPs has been found to have no impact on structural behavior, and paving the invert has been found to improve the structural performance [8]. Generally, a rehabilitated pipe can carry higher loads than a pipe before rehabilitation $[9,10]$. If a CSP is used to rehabilitate a reinforced concrete (RC) pipe, the load-sharing theory can be used to estimate the test-loading capacity of the rehabilitated pipe, and the level of corrosion of the RC pipe has little impact on the test-loading capacity $[11,12]$. 
Some facets of the existing research on slip-lined pipes, for example, the influencing factors of the strength of the rehabilitated structure and the contact state between different materials, can provide a reference for the research of rehabilitated RC slab culverts; however, the mechanical properties of an RC slab are very different from those of an $\mathrm{RC}$ pipe. Some field tests have proven that the stress state of a concrete bridge or a brick culvert rehabilitated with CSPs was effectively reduced and that the CSPs achieved a good reinforcement effect [13-15]. However, the investigations of RC slabs rehabilitated with CSPs remain insufficient. RC slabs rehabilitated with a CSP exhibit the following characteristics: (1) the CSP is constrained by the RC slab culvert and grout, which are stronger than soil, and the deformation of the CSP is limited; (2) the interface of the RC slab, grout, and CSP is characterized by contact and slippage that are different from those of the composite structure, and the CSP has an arch effect, which increases the difficulty of structural analysis; (3) with the transformation of the structural system, the failure mode of the rehabilitated structure changes, as does the corresponding mechanical model; (4) the grout cannot transfer tension but can only transfer pressure, thereby increasing the complexity of the role of cracked grout in the reinforcement system.

Recently, increasingly more CSPs have been used to rehabilitate RC slab culverts in China, but engineers only design a CSP as a new culvert, and the working principle of the rehabilitated structure is not clear. Therefore, it is necessary to investigate the mechanical characteristics of the rehabilitated structure to provide a reference for engineering applications. Against this background, in the present research, a series of destructive tests were conducted to explore the calculation method and influencing factors of load-carrying capacity of RC slab culverts rehabilitated with grouted CSPs. The research results of this paper can provide effective theoretical guidance for engineering application, so that designers can reasonably design the rehabilitation project according to the calculation formula and realize the target load-carrying capacity of the rehabilitated system.

\section{Experiment Description}

2.1. RCSlabs. Five laboratory-manufactured RC slabs were used in this experiment, each of which had a length of $2600 \mathrm{~mm}$, a width of $500 \mathrm{~mm}$, and a thickness of $150 \mathrm{~mm}$. Double-layer steel bars (HRB400) were arranged in the RC slabs with a protective layer thickness of $30 \mathrm{~mm}$; a $3 \phi 12$ arrangement was adopted for the upper steel bars, while a $6 \phi 16$ arrangement was adopted for the lower steel bars. The strength grade of the RC slabs was C40, which represents a compressive strength of $40.375 \mathrm{MPa}$ and an elastic modulus of $32.5 \mathrm{GPa}$. The strength grade of the steel bars was HRB400 with a minimum yield strength of $400 \mathrm{MPa}$ and a tensile strength of $575 \mathrm{MPa}$, and the elastic modulus of the steel bars was $210 \mathrm{GPa}$. The RC slabs were placed directly on the integral foundations, and the lap length was $150 \mathrm{~mm}$.
2.2. Integral Foundation. The integral foundation, which had a length of $3000 \mathrm{~mm}$ and a height of $1500 \mathrm{~mm}$, was a $\mathrm{U}$-shaped foundation formed by two piers connected with a bottom plate. The piers had a thickness of $350 \mathrm{~mm}$ and a width of $500 \mathrm{~mm}$, and three layers of $6 \phi 18$ steel bars were arranged in the piers. The bottom plate had a thickness of $200 \mathrm{~mm}$ and a width of $500 \mathrm{~mm}$, and two layers of $6 \phi 18$ steel bars were arranged in the plate. A groove was arranged at the top of the pier to place the RC slab, which had a length of $170 \mathrm{~mm}$ and a depth of $150 \mathrm{~mm}$.

2.3. CSPs. The CSPs were semicircular with an inner diameter of $1000 \mathrm{~mm}$ and were purchased from the manufacturer. The corrugation amplitude of the CSPs was $55 \mathrm{~mm}$ with a period of $200 \mathrm{~mm}$ and an intact wall thickness of $3 \mathrm{~mm}$. The designation of the CSPs was Q235, and they had a minimum yield strength of $235 \mathrm{MPa}$, a minimum tensile strength of $370 \mathrm{MPa}$, and an elastic modulus of $210 \mathrm{GPa}$. Unbalanced channels were used to connect the CSPs and the foundation, and the channel was connected with the foundation and CSPs by M20 expansion bolts and highstrength bolts, respectively.

2.4. Grout. Many materials can be used for grout, including foamed cement banking, cement mortar, fine aggregate concrete, and ordinary concrete. Considering that concrete is usually used in China [16-18], two types of grouts were used, namely, C30 concrete and M5 cement mortar. The C30 concrete had a compressive strength of $30.35 \pm 2.00 \mathrm{MPa}$ and an elastic modulus of $30 \mathrm{GPa}$, while the M5 cement mortar had a compressive strength of $3.37 \mathrm{MPa}$ and an elastic modulus of $6.08 \mathrm{GPa}$. The thickness of the grout at both the foot and the crown of the CPSs was $95 \mathrm{~mm}$.

2.5. Specimens. A total of five specimens were used in this experiment: (1) an RC slab rehabilitated with a grouted CSP (RRCS1 hereafter), (2) an RC slab rehabilitated with a grouted CSP (RRCS2 hereafter), (3) a preloaded RC slab rehabilitated with a grouted CSP (RRCS3 hereafter), (4) a preloaded RC slab rehabilitated with a grouted CSP (RRCS4 hereafter), and (5) an RC slab rehabilitated only with grout (RRCS5 hereafter). The grout used in RRCS1 was M5 cement mortar, whereas the grout used for the other specimens was C30 concrete. The difference between RRCS3 and RRCS4 was that the RC slab used in RRCS3 was preloaded to failure, whereas that used in RRCS4 was not. The details of the specimens are presented in Figure 1, and the loading scheme is illustrated in Figure 2.

2.6. Loading. This study enables a better understanding of the performance of $\mathrm{RC}$ slabs rehabilitated with grouted CSPs. A midspan single-point loading experiment was conducted in this study, and a string potentiometer with an accuracy of $0.1 \mathrm{~mm}$ was used to measure the vertical displacement of the midspan.

A load was applied to the specimens using a $1500 \mathrm{kN}$ hydraulic actuator that was attached to a reaction frame over 

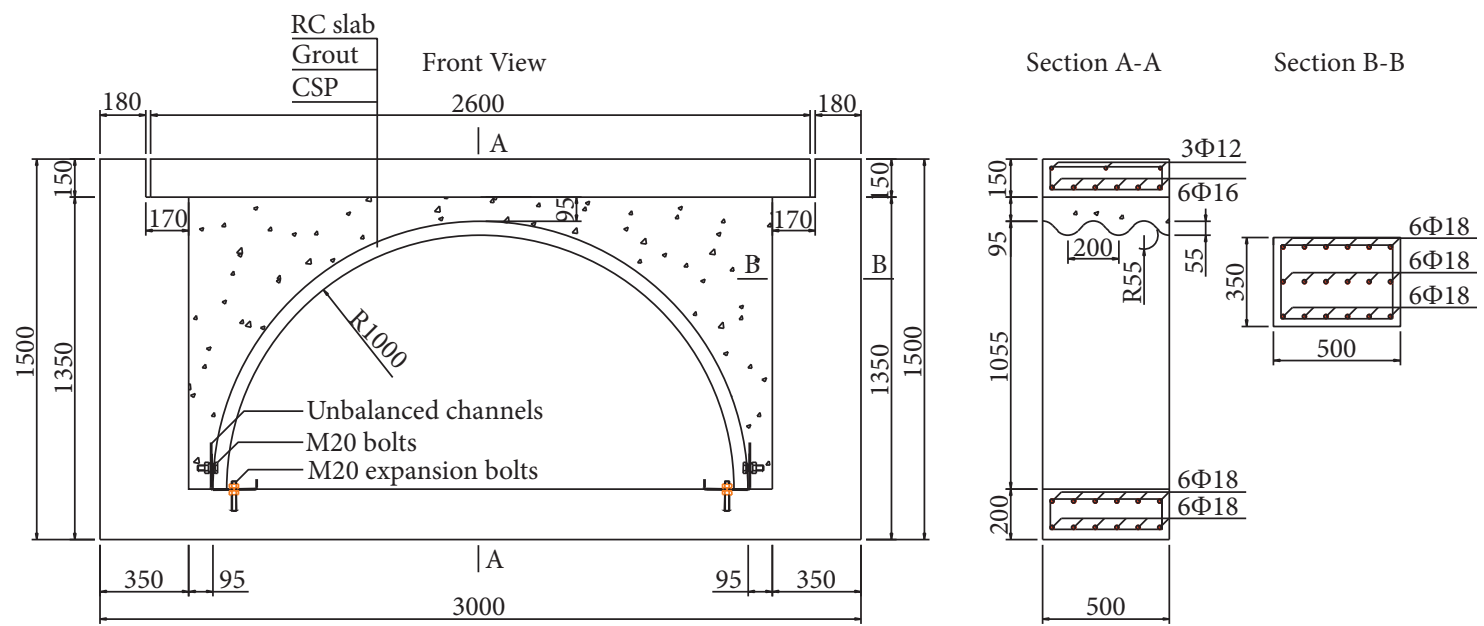

FIgURE 1: The details of the test specimens.

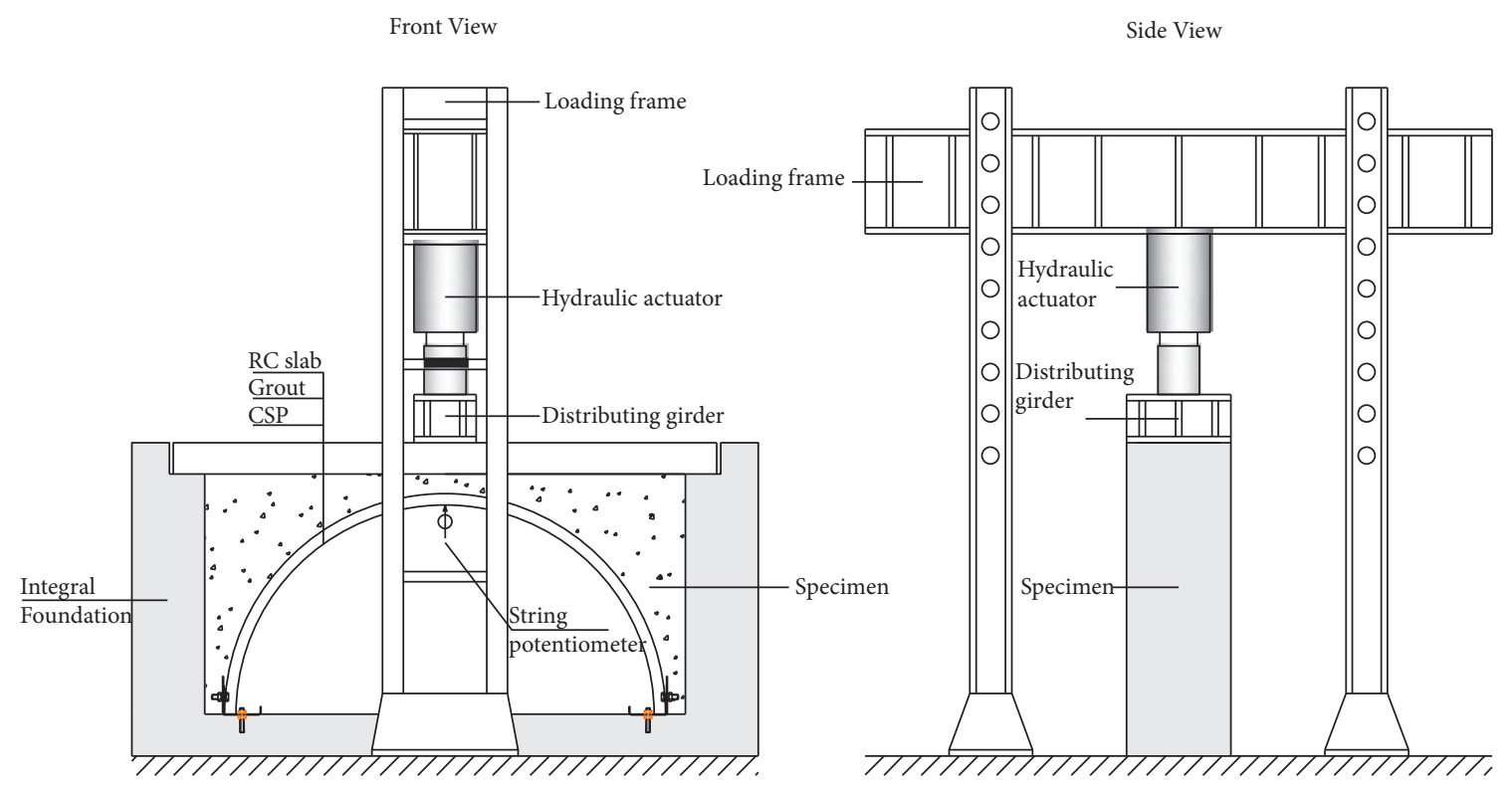

Figure 2: The schematic diagram of the loading frame.

the specimens. A distributing girder was used to ensure that the concentrated load could not cause the deterioration of the specimens or stress concentration. The specimens were loaded to the ultimate test-loading capacity at a loading rate of $15 \mathrm{kN} / \mathrm{min}$, and the loading was paused at various stages to observe the experimental phenomena.

\section{Experimental Results}

3.1. RC Slab. In this single-point experiment, the RC slab, which was a flexural member, was mainly subjected to a bending moment before rehabilitation. The RC slab exhibited good ductility throughout the experimental process, which conformed to the failure characteristics of the underreinforced beam. It can be seen from the load-displacement curve shown in Figure 3 that the RC slab had a yield strength of $116.52 \mathrm{kN}$ and an ultimate strength of $130 \mathrm{kN}$.
3.2. Rehabilitated System. Specimens RRCS1-5 were all RC slabs rehabilitated with grouted CSPs, and their load-displacement curves had the same shape; that is, each curve was basically a straight line before point (a). After point (a) was reached, the grout began to crack, and the slope of the loaddisplacement curve decreased and the curve was slightly inclined.

The experimental results of specimens RRCS3, RRCS4, and RRCS2 revealed that the preloading truly reduced the test-loading capacity of the rehabilitated system $(667.03 \mathrm{kN}$ and $683.89 \mathrm{kN}$ versus $735.4 \mathrm{kN}$, respectively), but preloading to failure or not to failure had little effect on the test-loading capacity $(667.03 \mathrm{kN}$ versus $683.89 \mathrm{kN})$. However, the RC slab preloaded to failure (RRCS3) had a lower vertical displacement in the midspan of its rehabilitated system than the RC slab not preloaded to failure (RRCS4) when the maximum test-loading capacity of the rehabilitated system was reached ( $9.59 \mathrm{~mm}$ versus $14.17 \mathrm{~mm}$, respectively). Moreover, 


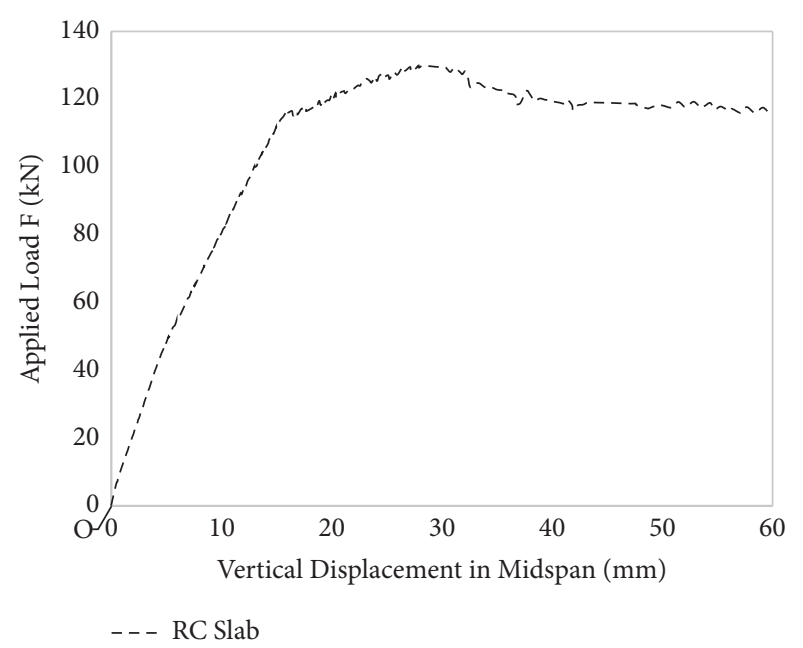

FIgURE 3: The relationship between the load and displacement for the RC slab.

it can be seen from Figure 4 that the vertical displacements of the midspans of the preloaded rehabilitated systems (RRCS3 and RRCS4) were both lower than that of the unpreloaded rehabilitated system (RRCS2) $(9.59 \mathrm{~mm}$ and $14.17 \mathrm{~mm}$ versus $17.21 \mathrm{~mm}$, respectively) when they reached the maximum test-loading capacity.

Generally, the load-displacement curves of the three specimens were similar in shape, and their grout-cracking points (point (a)) were close to each other. However, the ductilities of the three specimens after failure were quite different; that of RRCS3 (preloaded to failure) was the worst, followed by that of RRCS4 (not preloaded to failure), and that of RRCS2 (unpreloaded) was the best.

It can be seen from Figure 5 that the maximum testloading capacity of RRCS5 (the rehabilitated system without a CSP) was much lower than that of RRCS2 $(536.64 \mathrm{kN}$ versus $735.4 \mathrm{kN}$, respectively), and the difference between them was $198.76 \mathrm{kN}$ (this represents the test-loading capacity provided by the CSP). This finding indicates that the CSP did indeed play a role in the rehabilitated system, but the main contribution of the test-loading capacity of the rehabilitated system was provided by the RC slab and grout (73\%), whereas the CSP contributed $27 \%$ of the test-loading capacity. The two curves for RRCS2 and RRCS5 were found to be strikingly similar before reaching the maximum testloading capacity but had different amplitudes. From this point, the grout played an important role in strengthening the RC slab. The biggest difference between the two curves was that the ductility of RRCS2 was better than that of RRCS5 after reaching the maximum test-loading capacity due to the internal support of the CSP. Interestingly, the vertical displacements of the midspans of RRCS2 and RRCS5 were basically the same when the maximum test-loading capacity was reached. This indirectly indicates that the RC slab, grout, and CSP all reached their maximum test-loading capacities when the rehabilitated system reached its ultimate test-loading capacity.

Figure 6 reveals that the maximum test-loading capacity of RRCS1 was lower than that of RRCS2. Based on this, it can

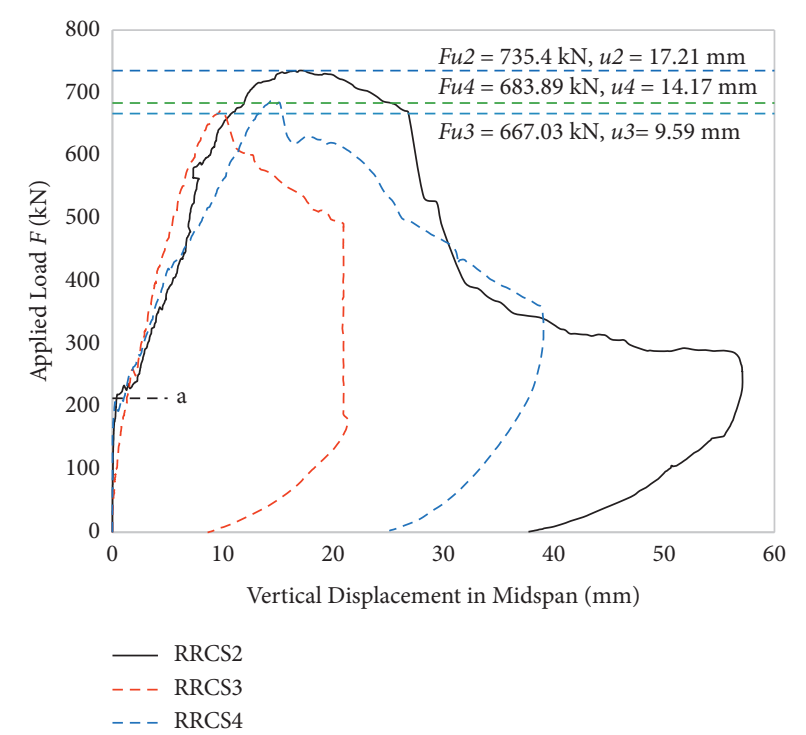

FIgURE 4: The relationship between the load and displacement for RRCS2, RRCS3, and RRCS4.

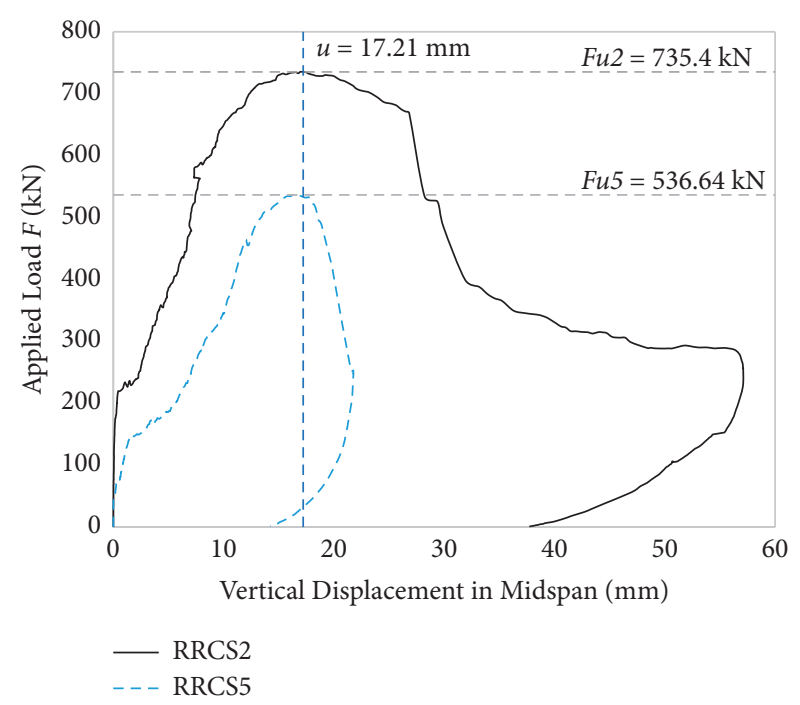

Figure 5: The relationship between the load and displacement for RRCS2 and RRCS5.

be concluded that the low grout strength resulted in the low test-loading capacity of the rehabilitated system. Moreover, the vertical displacements of the midspans of RRCS1 and RRCS2 were basically the same when the specimens reached the maximum test-loading capacity, and these specimens had the same ductility after reaching their maximum testloading capacity.

3.3. Strain and Curvature of CSPs. The cross-sectional strains of CSPs are helpful for distinguishing the bonded condition of the RC slab, grout, and CSP. If the RC slab, grout, and CSP are fully bonded in the midspan, the strains of the CSP should be an oblique straight line, and the strains at the crest and valley of the CSP should be tensile strains; if there is no 


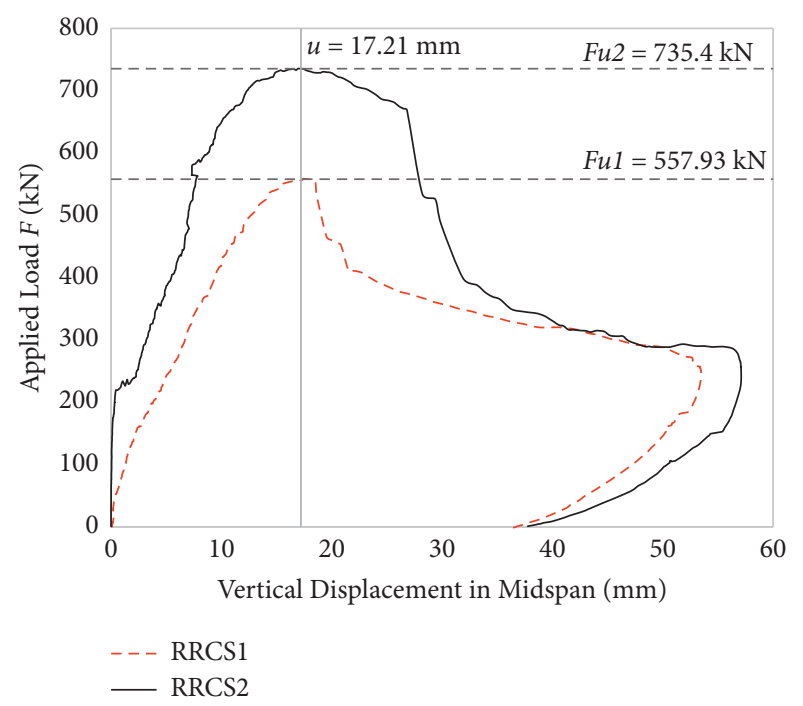

FIgURE 6: The relationship between the load and displacement for RRCS1 and RRCS2.

bonding between the CSP and grout, the strains at the crest and valley should be compressive and tensile strains, respectively. These two cases correspond to the strain distributions of full and partial bonding, as shown in Figure 7.

Figure 8 presents the strain distributions at the crest and valley of the CSP in RRCS2 at four different loading stages, namely, before grout cracking $(F=100 \mathrm{kN})$, during grout cracking $(F=216.39 \mathrm{kN})$, before the rehabilitated system reached the ultimate test-loading capacity $(F=600 \mathrm{kN})$, and at the point at which the rehabilitated system reached the ultimate test-loading capacity $(F=735.4 \mathrm{kN})$. It can be seen from Figure 8 that the strains at the vault of the CSP were all tensile, and the crest strain was less than the valley strain, which indicates that the CSP and grout were bonded before and during grout cracking (similar to the full bonding case exhibited in Figure 7). In contrast, at the crown of the CSP, the crest strain was compressive and the valley strain was tensile, which indicates that the CSP and grout slipped, and the CSP began to act independently before and at the point at which the ultimate test-loading capacity was reached.

The yield strain of steel was about $0.0011\left(1100 \times 10^{-6}\right)$, so when the specimen reached its ultimate test-loading capacity, the strains at the crown of the CSP already exceeded the yield strain of steel; this indicates that a plastic hinge had been formed at this time. If the test-loading capacity estimation is based on the ultimate test-loading capacity, the contribution of the CSP should be calculated via the use of a plastic theory.

The curvatures reflect the bending deformation of the CSP. When the strains of the CSP are less than the yield strains, the bending moment can be calculated by transforming the strains into stresses via Hooke's law; however, once the strains of the CSP are greater than the yield strains, Hooke's law is no longer applicable. Moreover, the stressstrain relationship of a cold-pressed CSP is unknown, and it is difficult to obtain the stresses. Therefore, the mechanical performance of the CSP after yielding was analyzed via the curvature, which was calculated as follows [19]:

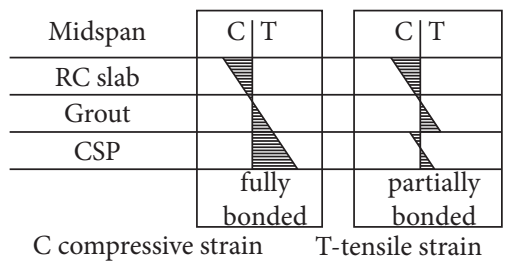

FIgURE 7: The strain distributions of different bonding conditions.

$$
\kappa=\frac{\varepsilon_{2}-\varepsilon_{1}}{h},
$$

where $\kappa$ is the curvature $\left(10^{-6} / \mathrm{mm}\right)$ and $\varepsilon_{1}$ and $\varepsilon_{2}$ are, respectively, the crest and valley strains.

Figure 9 presents the curvature distributions of the CSP in two stages, namely, the yield stage of the CSP and the ultimate stage. The curvature was found to increase with the increase of the applied loads, and the curvature distributions were the largest when the specimens reached the ultimate test-loading capacity. The curvature distributions of the cross sections in the two loading stages were similar. The crown of the CSP was subjected to a positive bending moment, resulting in downward deformation, while the other sections were subjected to a negative bending moment, resulting in upward deformation. This phenomenon indirectly indicates that the CSP may have only carried applied loads (active action) directly at the crown, while the other sections were constrained by the grout (passive action) and not directly subjected to applied loads. If a twohinged semicircular arch without the restraint of grout is subjected to vertical load, the inflection point will appear in the inclined direction at an angle of $45^{\circ}$ relative to the vault. However, the inflection point shown in Figure 8 was less than $45^{\circ}$; this indicates that the grout provided stronger lateral restraint for the foot and shoulder of the CSP than soil; that is, the foot of the CSP cannot rotate outward.

\section{Failure Characteristics of the Rehabilitated System}

Specimens RRCS1-5 had the same failure characteristics. Taking RRCS2 as an example, Figure 10 presents the crack distributions of the rehabilitated system. When RRCS2 was loaded to $230 \mathrm{kN}$, vertical bending cracks appeared at the crown of the grout, and horizontal bending cracks appeared at the middle height of the side of the grout. When loaded to $300 \mathrm{kN}$, vertical bending cracks appeared at the midspan of the RC slab. When loaded to $310 \mathrm{kN}$, shear cracks appeared in the RC slab and developed obliquely downward from the edge of the distributing girder at an approximate angle of $45^{\circ}$. When loaded to $550 \mathrm{kN}$, shear cracks appeared in the grout and also developed obliquely downward at an approximate angle of $45^{\circ}$. When loaded to the ultimate testloading capacity, the width of the shear cracks in the RC slab and grout increased, the vertical deformation of the CSP also increased, and the shoulders buckled plastically. It can be inferred from the experimental phenomena that shear failure occurred in the RC slab and grout, whereas bending failure occurred in the CSP, and plastic hinges appeared at the crown and shoulders of the CSP. Thus, the ultimate test- 

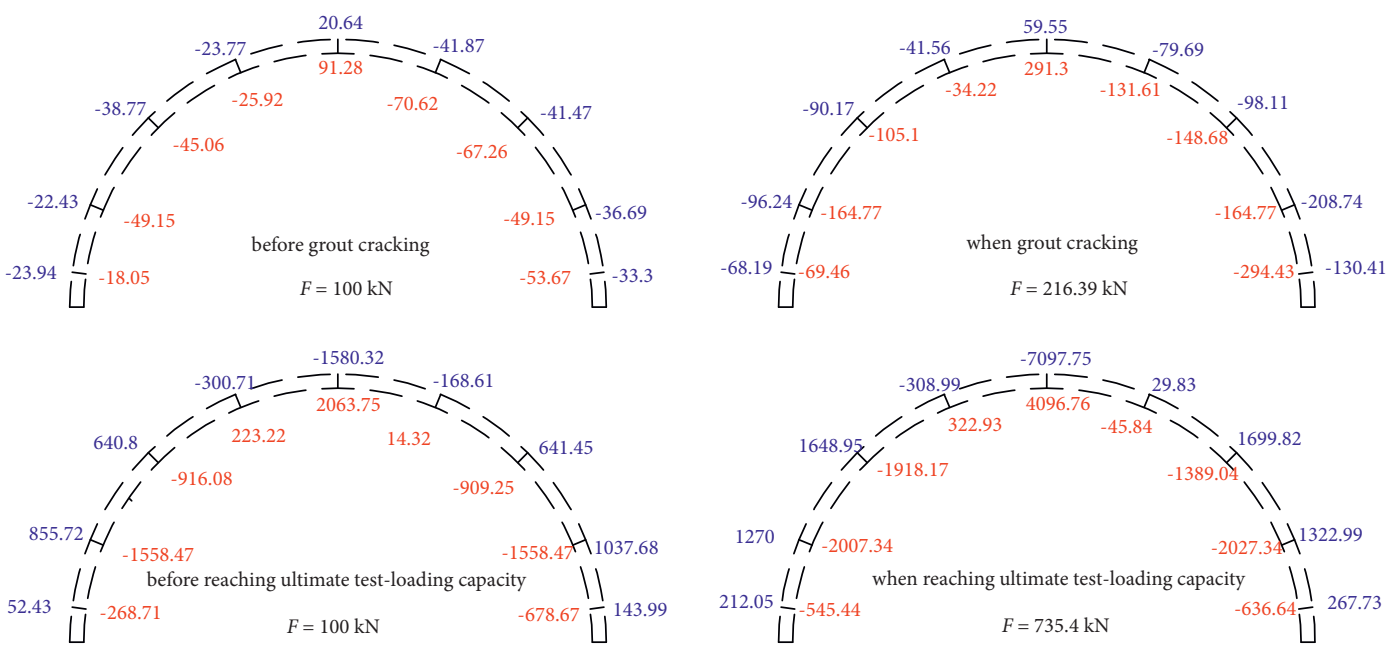

FIgURE 8: The cross-sectional strains of the CSP (unit: $10^{-6}$ ).
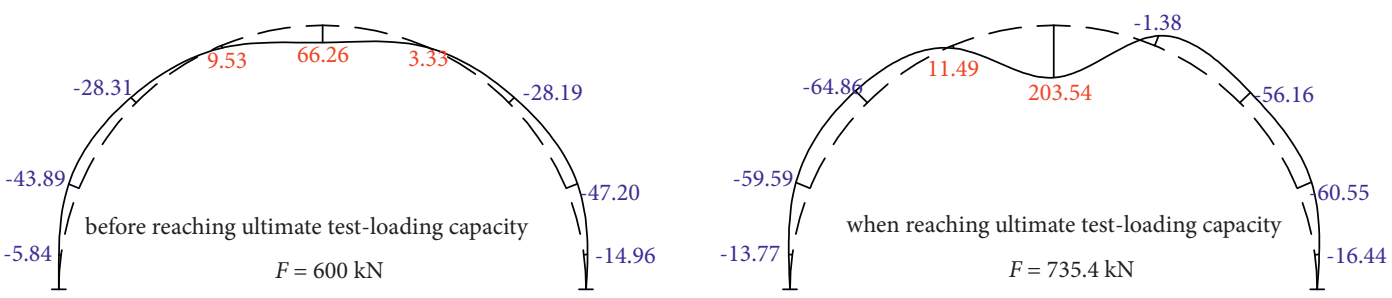

Figure 9: The sectional curvatures of the CSPs.

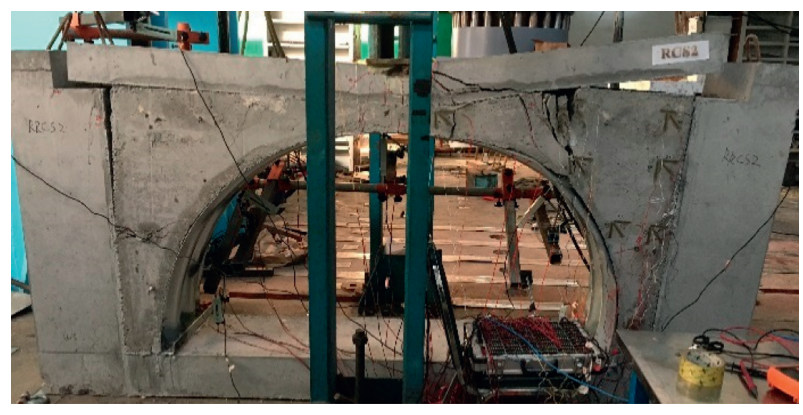

(a)

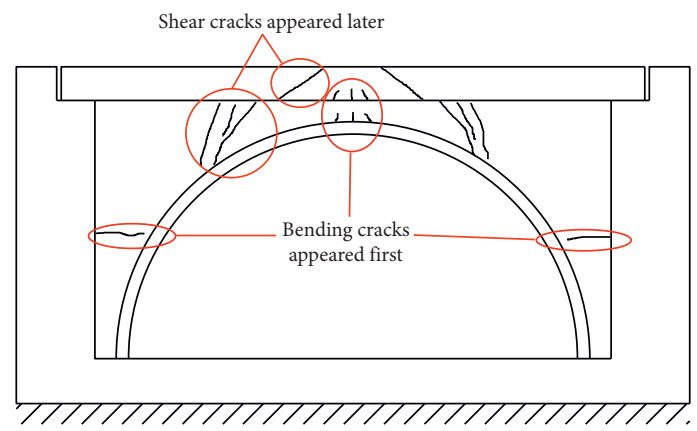

(b)

FIgURE 10: The failure characteristics: (a) overall failure pattern; (b) schematic diagram of cracks.

loading capacity of the rehabilitated system may depend on the shear capacity of the RC slab and grout and the flexural carrying capacity of the CSP.

\section{Estimation of the Test-Loading Capacity}

Based on the experimental phenomena, shear failure occurred in the RC slab and grout, and horizontal slippage occurred at their interface; thus, they did not bond together. In addition, Figure 5 shows that the deformations of specimens RRCS5 and RRCS2 were the same, which indicates that the rehabilitated system reached its ultimate test-loading capacity when the RC slab and grout were damaged.

Moreover, because bending failure occurred in the CSP, it can be concluded that the RC slab and grout were subjected to shear forces, while the CSP was separately subjected to a bending moment, and the rehabilitated system reached its ultimate test-loading capacity when the RC slab and grout reached their shearing strengths. The maximum test-loading capacity of the rehabilitated system was the sum of the shear capacities of the RC slab and grout and the bending capacity of the CSP. Therefore, the calculation sketch in Figure 11 was used to estimate the test-loading capacity of the rehabilitated system. The shear failure surface was an oblique section downward from the edge of the distributing girder to the crown of CSPs with a hypothetical angle of $45^{\circ}$, and the applied load $F$ should satisfy the following equation:

$$
F=F_{1}+F_{2}+F_{3}
$$



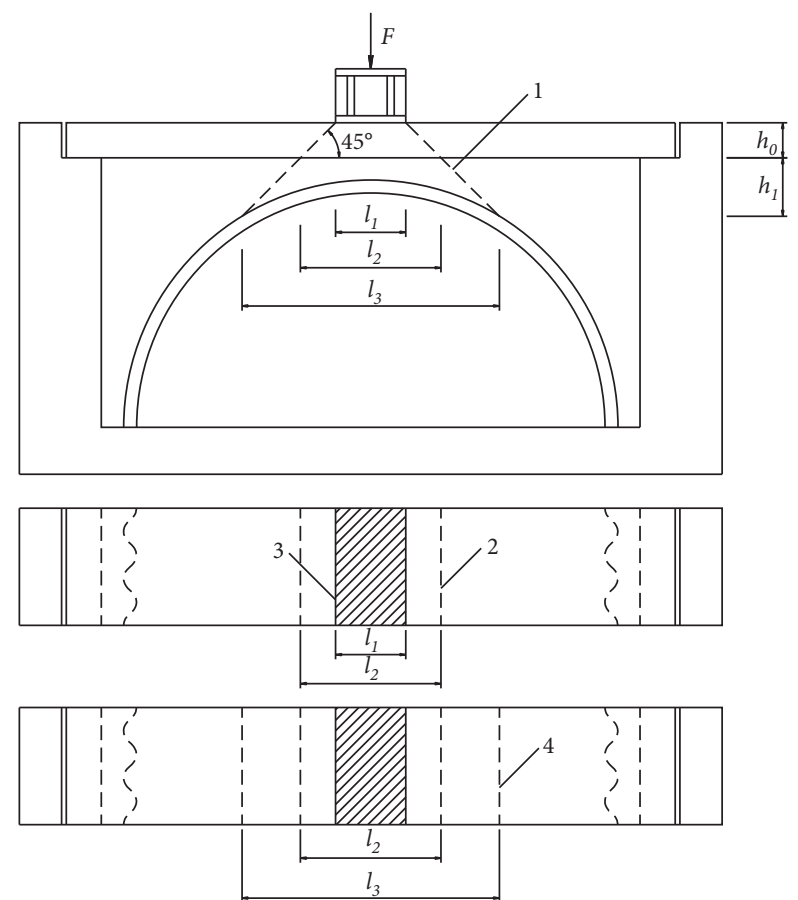

FIgURE 11: The calculation sketch of the rehabilitated system. (1) Shear surface of the RC slab and grout; (2) shear failure bottom line of the RC slab; (3) distributing girder side line; (4) shear failure bottom line of the grout.

where $F$ is the applied load carried by the rehabilitated system, $F_{1}$ is the shear capacity of the RC slab, $F_{2}$ is the shear capacity of the grout, and $F_{3}$ is the bending capacity of the CSPs.

The shear capacity of the RC slab and grout can be calculated using the approach specified in the Concrete Structures Design Code [20] as follows:

$$
\begin{aligned}
& F_{1}=0.5 f_{t 1} A_{1}+0.8 f_{y v} A_{s v}, \\
& F_{2}=0.7 \beta_{h} f_{t 2} A_{2},
\end{aligned}
$$

where $f_{t 1}$ is the characteristic tensile strength of the concrete in the RC slab, $f_{t 2}$ is the characteristic tensile strength of the grout, and $\beta_{h}$ is the influence coefficient of the cross-sectional height, which should be 1.0 when the cross-sectional height is not more than $800 \mathrm{~mm}$ and 0.9 when the crosssectional height is not less than $2000 \mathrm{~mm}$. Moreover, $A_{1}$ is the total area of the shear surface of the RC slab, which is equal to $\left(l_{2}-l_{1}\right) / \cos 45^{\circ}$, and $A_{2}$ is the total area of the shear surface of the grout, which is equal to $\left(l_{3}-l_{2}\right) / \cos 45^{\circ}$. Furthermore, $f_{y v}$ is the characteristic tensile strength of the stirrup, $A_{s v}$ is the section area of the stirrups intersecting the shear surface of the RC slab, $l_{1}$ is the width of the distributing girder, $l_{2}$ is the length of the applied load diffused to the bottom of the RC slab, and $l_{3}$ is the length of the applied load diffused to the bottom of the grout.

In a soil-steel system, the CSP is usually simplified as a two-hinged arch. However, due to the lateral restraint of the grout, the rotation of the foot of the CSP is restrained, thereby greatly improving the test-loading capacity of the CSP. Thus, in the rehabilitated system, the CSP was simplified as a fixed arch, the flexural capacity of which can be calculated using the approach specified for arch bridges [21]. At this time, the bending moment at the crown of the CSP can be calculated by equation (4) and should be less than the plastic bending capacity $f_{\mathrm{CSP}} \cdot Z$. Moreover, $F_{3}$ can be calculated by equation (5).

$$
\begin{aligned}
M_{c} & =\frac{F_{3} R}{8}=f_{\mathrm{CSP}} Z, \\
F_{3} & =\frac{8 f_{\mathrm{csp}} Z}{R},
\end{aligned}
$$

where $F_{3}$ is the bending capacity of the CSP, which is the resultant force of uniformly distributed loads acting on the crown of the CSP, $R$ is the mean radius of the CSP, $f_{\mathrm{CSP}}$ is the characteristic yield strength of the CSP, and $Z$ is the plastic section modulus of the CSP.

Specimen RRCS2 was taken as an example to illustrate the calculation process of the test-loading capacity; while the characteristic material strength was used in this process, the design values of material strength should be adopted for structural design. The characteristic tensile strengths of C40 concrete, C30 concrete, and M5 mortar were, respectively, 2.39, 2.01, and $0.1 \mathrm{MPa}$, and the characteristic yield strength and cross-sectional area of the stirrups were, respectively, $400 \mathrm{MPa}$ and $123 \mathrm{~mm}^{2}$. Because the horizontal projection length of the shear cracks $(150 \mathrm{~mm})$ in the RC slab was less than the spacing of the stirrups $(180 \mathrm{~mm})$, the shear cracks would not intersect with the stirrups, and the stirrups would not provide any shear capacity. Moreover, the values of $l_{1}, l_{2}$, and $l_{3}$ of the specimens were, respectively, 183, 483, and $847 \mathrm{~mm}$ (these values can be measured by drawing software, such as AUTO CAD). The characteristic yield strength of the CSP was $235 \mathrm{MPa}$, the plastic section modulus was $62.351 \mathrm{~mm}^{3} / \mathrm{mm}$, the mean radius of the CSP was $0.5 \mathrm{~m}$, the widths of the RC slab and CSP were $500 \mathrm{~mm}$, and the value of $\beta_{h}$ was 1.0 .

$$
\begin{aligned}
F_{1} & =0.5 f_{t 1} A_{1}+0.8 f_{y v} A_{s v} \\
& =0.5 \times 2.39 \times 500 \times(483-183) \times \sqrt{2} \times 10^{-6}+0 \\
& =253.5 \mathrm{kN}, \\
F_{2} & =0.7 \beta_{\mathrm{h}} f_{t 2} A_{2} \\
& =0.7 \times 1.0 \times 2.01 \times 500 \times(847-483) \times \sqrt{2} \times 10^{-6} \\
& =362 \mathrm{kN}, \\
F_{3} & =\frac{8 f_{\mathrm{csp}} Z}{R} \\
& =\frac{8 \times 235 \times 62.351 \times 500 \times 10^{-6}}{0.5} \\
& =117.3 \mathrm{kN}, \\
F & =F_{1}+F_{2}+F_{3} \\
& =732.8 \mathrm{kN} .
\end{aligned}
$$


The calculated test-loading capacity of RRCS2 $(732.8 \mathrm{kN})$ was very close to the experimental result $(735.4 \mathrm{kN})$, and the calculated and experimental results of other specimens are summarized in Table 1. It is evident that the maximum difference between the theoretical and experimental results was less than $30 \%$, and the minimum difference between them was $0 \%$, which indicates that the calculation method is reasonable and can be used to estimate the test-loading capacity of a rehabilitated system. If the design value of material strength was adopted, the calculated results would be more conservative.

\section{Discussion}

It can be concluded that the test-loading capacity of the RC slab depends on its flexural capacity, while that of the rehabilitated system depends on the shear capacity of the RC slab and grout after rehabilitation, which can be determined based on the test-loading capacity of these specimens and the failure phenomena. Because preloading will cause the RC slab to have different residual flexural capacities, if the testloading capacity of the rehabilitated system depends on the flexural capacity of the RC slab, it should be substantially different from the test-loading capacity of the original system. However, this was not the case with the experimental results; the test-loading capacities of RRCS2, RRCS3, and RRCS4 were found to be very close. The rehabilitated systems consisted of an RC slab, grout, and a CSP, and an arch effect was produced by the CSP and grout. This arch effect greatly improved the test-loading capacity of the rehabilitated system, resulting in the flexural strengths of the RC slab and grout being higher than the shearing strengths; thus, the rehabilitated system can only undergo shear failure.

Specimen RRCS2 represents an RC slab rehabilitated with a grouted CSP, whereas specimen RRCS5 represents an RC only rehabilitated with only grout. However, RRCS2 and RRCS5 had the same vertical deformation when they reached their ultimate test-loading capacities. This phenomenon indicates that, regardless of the presence of a CSP, once the RC slab and grout undergo shear failure, the rehabilitated system will be damaged. Before reaching the ultimate test-loading capacity, the flexible CSP does not change the ductility of the rehabilitated system; on the contrary, it changes the ductility at the failure stage, and, consequently, the rehabilitated system will not collapse suddenly. In these experiments, the CSP and grout were found to, respectively, contribute $27 \%$ and $73 \%$ to the improvement in the test-loading capacity, from which it can be inferred that the ultimate test-loading capacity of the rehabilitated system was mainly provided by the grout. However, whether the CSP can play a greater role is related to its own bending stiffness; the greater the bending stiffness, the greater the role it will play.

The flexural strength of the existing RC slab should be ignored when the slab is rehabilitated with a semicircular CSP, as the rehabilitated slab and grout will undergo shear failure instead of flexural failure. In such a rehabilitated system, due to the arch effect of the CSP and grout, the failure of the RC slab and grout will be changed from flexural
TABLE 1: The calculated and experimental results of the test-loading capacity.

\begin{tabular}{lccc}
\hline Specimen & $f_{c}(\mathrm{kN})$ & $f_{t}(\mathrm{kN})$ & $\left|f_{c}-f_{t}\right| / f_{t}(\%)$ \\
\hline RRCS1 & 388.9 & 557.93 & 30 \\
RRCS2 & 732.8 & 735.4 & 0 \\
RRCS3 & 732.8 & 667.03 & 10 \\
RRCS4 & 732.8 & 683.89 & 7 \\
RRCS5 & 615 & 536.64 & 15 \\
\hline
\end{tabular}

Note. $f_{t}$ : experimental results; $f_{c}$ : calculated results.

failure (before rehabilitation) to shear failure (after rehabilitation). Therefore, the shear strengths of the RC slab and grout were used to estimate the test-loading capacity of the rehabilitated system. However, the CSP underwent flexural failure, so the bending strength should be used to estimate the test-loading capacity of the rehabilitated system. The restraint of the grout on the CSP resulted in differences from a soil-CSP system; the side wall and grout provided strong lateral restraint for the CSP in the rehabilitated system, which caused the test-loading capacity of the CSP to be much higher than that of a soil-CSP structure. The horizontal restraint of the grout and side wall was found to be very beneficial to the restriction of the foot deformation of the CSP; consequently, the arch foot should be simplified to a fixed constraint. In addition, the applied load acting on the midspan will be diffused into a range at the crown of the CSP by the RC slab and grout, and the grout at the shoulders of the CSP will also restrain the vertical deformation of the CSP, which appears as vertical loads acting on the shoulders of the CSP. Taking these two factors into consideration, the load acting on the CSP was simplified as a uniform load distribution across the full span of the CSP. For this reason, a CSP with small corrugation can provide a high test-loading capacity in the rehabilitated system, which is very different from the analysis principle of the soil-CSP structure.

It is noteworthy that a semicircular arch was used to rehabilitate the RC slabs in this research, and the test-loading capacity estimation was based on the experimental results and phenomena. If an RC slab with a large span is rehabilitated with a box-type CSP, the failure mechanism of the rehabilitated system will be different; the flexural failure of the RC slab, grout, and CSP will be more likely to occur in the midspan (at the crown of the arch), and the ultimate testloading capacity of the rehabilitated system may primarily depend on the flexural capacities of the RC slab, grout, and CSP.

\section{Conclusions}

The current investigation was undertaken to ascertain the influencing factors and propose the practical calculation method of load-carrying capacity of RC slabs rehabilitated with grouted CSPs. Five specimens were tested in singlepoint loading experiments of the midspans of the RC slabs. The following key conclusions were drawn from this research:

(1) Regardless of whether the RC slab undergoes flexural failure, it will have little influence on the test-loading 
capacity of the rehabilitated system. After rehabilitation, shear failure will occur in the RC slab and grout, and the arch effect will be formed in the CSP and grout. Moreover, the ultimate test-loading capacity of the rehabilitated system will depend on the shear capacity of the RC slab and grout, as well as the flexural capacity of the CSP. In addition, the CSP will be subjected to strong horizontal restraint, which will also improve the flexural capacity of the semicircular CSP arch. Therefore, the flexural capacity of an RC slab culvert can be greatly improved via rehabilitation with a grouted CSP.

(2) The specimens with high-strength grout exhibited significant increases in their test-loading capacities; the greater the strength of the grout, the higher the test-loading capacity of the rehabilitated system. In other words, the higher the shear strength of the concrete of the RC slab and the grout, the greater the test-loading capacity of the rehabilitated system. This means that the RC slab and grout greatly contribute to the test-loading capacity of the rehabilitated system. Moreover, the CSP changes the ductility of the rehabilitated system at the failure stage.

(3) The estimation method of the test-loading capacity of the rehabilitated system based on the shear capacity of the RC slab and grout and the flexural capacity of the CSP is reasonable. The maximum difference between the theoretical and experimental results was found to be less than $30 \%$, and the minimum difference between them was $0 \%$. The designers can effectively design the rehabilitation project according to this practical calculation method.

\section{Abbreviations}

RRCS1: RC slab rehabilitated with a grouted CSP; M5 cement mortar was used as grout

RRCS2: Unpreloaded RC slab rehabilitated with a grouted CSP; C30 concrete was used as grout

RRCS3: RC slab preloaded to failure rehabilitated with a grouted CSP; C30 concrete was used as grout

RRCS4: RC slab not preloaded to failure rehabilitated with a grouted CSP; C30 concrete was used as grout

RRCS5: RC slab rehabilitated with grout; C30 concrete was used as grout

$F_{u 1}$ : $\quad$ Maximum test-loading capacity of RRCS1

$F_{u 2}$ : Maximum test-loading capacity of RRCS2

$F_{u 3}$ : Maximum test-loading capacity of RRCS3

$F_{u 4}: \quad$ Maximum test-loading capacity of RRCS4

$F_{u 5}: \quad$ Maximum test-loading capacity of RRCS5

$u_{1}$ : Midspan vertical displacement corresponding to $F_{u 1}$

$u_{2}$ : Midspan vertical displacement corresponding to $F_{u 2}$

$u_{3}$ : Midspan vertical displacement corresponding to $F_{u 3}$ $u_{4}$ : $\quad$ Midspan vertical displacement corresponding to $F_{u 4}$

$u_{5}$ : Midspan vertical displacement corresponding to $F_{u 5}$

$\kappa: \quad$ Curvature $\left(10^{-6} / \mathrm{mm}\right)$

$\varepsilon_{1}$ : $\quad$ Crest strains of CSP

$\varepsilon_{2}$ : $\quad$ Valley strains of CSP

$F: \quad$ Applied load carried by the rehabilitated system

$F_{1}$ : $\quad$ Shear capacity of the RC slab

$F_{2}$ : $\quad$ Shear capacity of the grout

$F_{3}$ : $\quad$ Bending capacity of the CSP, which is the resultant force of uniformly distributed loads acting on the crown of the CSP

$f_{t 1}$ : Characteristic tensile strength of the concrete in the RC slab

$f_{t 2}$ : $\quad$ Characteristic tensile strength of the grout

$\beta_{h}$ : Influence coefficient of the cross-sectional height, which should be 1.0 when the cross-sectional height is not more than $800 \mathrm{~mm}$ and 0.9 when the cross-sectional height is not less than $2000 \mathrm{~mm}$

$A_{1}$ : $\quad$ Total area of the shear surface of the RC $\operatorname{slab}^{\circ}={ }^{\circ}\left(l_{2}-l_{1}\right) / \cos 45^{\circ}$

$A_{2}$ : $\quad$ total area of the shear surface of the grout $^{\circ}={ }^{\circ}\left(l_{3}-l_{2}\right) / \cos 45^{\circ}$

$f_{y v}: \quad$ Characteristic tensile strength of the stirrup

$A_{s v}$ : $\quad$ Section area of the stirrups intersecting the shear surface of the RC slab

$l_{1}$ : Width of the distributing girder

$l_{2}$ : $\quad$ Length of the applied load diffusing to the bottom of the RC slab

$l_{3}$ : $\quad$ Length of the applied load diffusing to the bottom of the grout

$R: \quad$ Mean radius of CSP

$f_{\mathrm{CSP}}: \quad$ Characteristic yield strength of CSP

$Z$ : $\quad$ Plastic section modulus of CSP

$f_{t}: \quad$ Experimental results

$f_{c}$ : $\quad$ Calculated results.

\section{Data Availability}

The data (experimental results) used to support the findings of this study are included in the article.

\section{Conflicts of Interest}

The authors declare that there are no conflicts of interest regarding the publication of this study.

\section{Acknowledgments}

This work was supported by the National Natural Science Foundation (Grant no. 52108142). The authors are grateful to Guangzhou Communication Investment Group Co., Ltd., and Hunan Jindi Corrugated Pipe Co., Ltd., for providing funds and experimental specimens. 


\section{References}

[1] Astm, Standard Guide for Insertion of Flexible Polyethylene Pipe into Existing Sewers, ASTM F585, West Conshohocken, PA, USA, 2013.

[2] SnapTite, Design Guide, SnapTite, Erie, PA, USA, 2013, http:// www.culvert-rehab.com/pdfs/2013_manual.pdf.

[3] J. Q. Zhao and L. Daigle, "Structural performance of sliplined watermain," Canadian Journal of Civil Engineering, vol. 28, no. 6, pp. 969-978, 2001.

[4] G. McAlpine, "Structural rehabilitation of semi elliptical concrete sewers," in Proceedings of Pipelines, pp. 1-7, ASCE, Reston, VA, USA, 2006.

[5] T. Smith, N. A. Hoult, and I. D. Moore, "Role of grout strength and liners on the performance of slip-lined pipes," Journal of Pipeline Systems Engineering and Practice, vol. 6, no. 4, Article ID 04015007, 2015.

[6] D. Becerril García and I. D. Moore, "Performance of deteriorated corrugated steel culverts rehabilitated with sprayedon cementitious liners subjected to surface loads," Tunnelling and Underground Space Technology, vol. 47, pp. 222-232, 2015.

[7] I. D. Moore and D. B. García, "Ultimate strength testing of two deteriorated metal culverts repaired with spray-on cementitious liners," Transportation Research Record: Journal of the Transportation Research Board, vol. 2522, no. 1, pp. 139147, 2015.

[8] J. Tetreault, N. A. Hoult, and I. D. Moore, "Pre- and postrehabilitation behaviour of a deteriorated horizontal ellipse culvert," Canadian Geotechnical Journal, vol. 55, no. 3, pp. 329-342, 2018.

[9] B. Simpson, I. D. Moore, and N. A. Hoult, "Experimental investigation of rehabilitated steel culvert performance under static surface loading," Journal of Geotechnical and GeoEnvironmental Engineering, vol. 142, no. 2, Article ID 04015076, 2016.

[10] B. Simpson, N. A. Hoult, and I. D. Moore, "Rehabilitated reinforced concrete culvert performance under surface loading," Tunnelling and Underground Space Technology, vol. 69, pp. 52-63, 2017.

[11] B. J. Li, L. S. Zhu, and X. S. Fu, "Influence of grout strength and residual deformation on performance of rehabilitated RC pipes," Journal of Pipeline Systems Engineering and Practice, vol. 11, no. 2, Article ID 04020003, 2020.

[12] B. J. Li, L. S. Zhu, and X. S. Fu, "Investigation of the loadsharing theory of the rc pipes rehabilitated with slip liners," Advances in Civil Engineering, vol. 2019, no. 8, Article ID 9594379, 2019.

[13] J. Vaslestad, A. Madaj, L. Janusz, and B. Bednarek, "Field measurements of old brick culvert slip lined with corrugated steel culvert," in Proceedings of the 83rd Annual Meeting of the Transportation-Research-Board, pp. 227-234, Washington, DC, USA, January 2004.

[14] J. Vaslestad, A. Madaj, L. Janusz et al., "Field measurements of long-span corrugated steel culvert replacing corroded concrete bridge," in Proceedings of the 82rd Annual Meeting of the Transportation-Research-Board, pp. 164-170, Washington, DC, USA, January 2002.

[15] S. Syachrani, H. S. Jeong, V. Rai, M. J. Chae, and T. Iseley, "A risk management approach to safety assessment of trenchless technologies for culvert rehabilitation," Tunnelling and Underground Space Technology, vol. 25, no. 6, pp. 681-688, 2010.
[16] C. Chen, "On consolidation of steel corrugated pipe culvert on expressways," Shanxi Architecture, vol. 42, no. 17, pp. 142-143, 2016.

[17] P. P. Shang, "Defect culvert reinforcement technology using corrugated plate on existing heavy haul railway," Railway Engineering, vol. 57, no. 8, pp. 50-53, 2017.

[18] Z. H. Wang, "On application of corrugated steel pipe culvert in road construction," Shanxi Architecture, vol. 38, no. 25, pp. 186-188, 2012.

[19] H. W. Liu, Mechanics of Materials (I), Higher Education Press, Beijing, China, 4th edition, 2004.

[20] Mohurd (Ministry of Housing and Urban-Rural Development), Code for Design of Concrete Structures, GB 50010-2010, National Standards of People's Republic of China, Beijing, China, 2011.

[21] CGDMHBC (Compile Group of Design Manual for Highway Bridge and Culvert), Arch Bridge, China Communication Press, Beijing, China, 1984. 